\title{
A MULHER NA NATUREZA
}

\author{
MARTINHO ALVES DA COSTA JUNIOR reflete sobre a tradição dos \\ nus alongados a partir da Baigneuse endormie, de Théodore \\ Chassériau
}

Certamente o estudo das artes comparadas ou por uma história da arte comparatista é um assunto que ganha notoriedade e entra de modo incisivo nos estudos contemporâneos, embora nunca, de fato, estivesse fora do escopo da disciplina.

Contudo, o que intriga ainda é o embate direto com as imagens, como de modo prático pode-se proceder em uma análise na qual esses elementos se conjuguem e suas características se acentuem com a presença de outras imagens e produções culturais.

É por este viés que este artigo se baliza. A imagem de 1850 de Théodore Chassériau, Baigneuse endormie près d’une source [Fig. 01] é o ponto de partida para que se possa compreendê-la em um espaço de relação, não apenas com outras imagens, mas avizinhando-se de outras artes e outros modos da produção da cultura contemporânea. Uma obra que claramente nos permite pensá-la na tradição dos nus alongados, sem negar uma forte e importante veia moderna. 


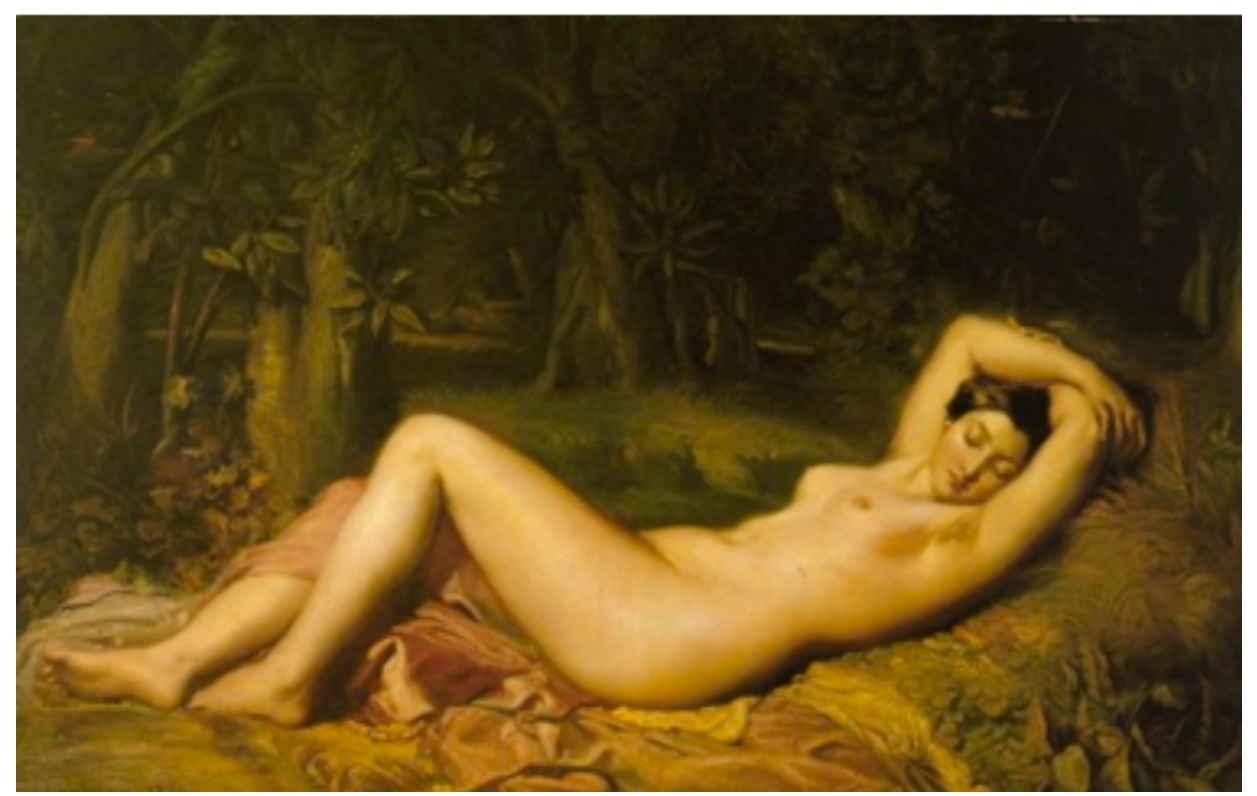

[Fig. 01] Théodore Chassériau, Baigneuse endormie près d'une source, 1850. Musée Calvet. 137 × 210 cm, óleo sobre tela.

Embora o título da obra sugira um distanciamento claro em relação ao espectador, a pose da modelo aproxima e convida o olhar. Adormecida, a banhista com os braços erguidos e cruzados sob a cabeça está envolta a uma paisagem ocre-esverdeada, onde as árvores formam uma espécie de ninho. A vegetação à esquerda da composição fecha-se em si quase como uma gruta. Sua cama, feita da relva, parece acolher perfeitamente seu corpo. As nádegas são protegidas por um drapeado, da roupa que escondia a exuberância do corpo nu.

A sexualidade aflora de modo particular: a pele brilhosa é como que suada e polida e os braços levantados deixam aparentes os pelos nas axilas. Diferentemente de uma deusa cuja ausência de pelos, sejam pubianos ou não, transmite um ideal de corpo, quase inalcançável, de pureza e contemplação. Os pelos aparentes, por sua vez, sugerem materialidade e uma sexualidade carnal e possível. Um tipo de nu alongado um pouco diverso daquele da tradição da academia. Basta pensar nas diversas imagens de Ingres, que foi seu mestre, nas quais raramente - para não afirmar a completa ausência - o tema é introduzido. Ao inserir os pelos nas axilas de sua banhista, Chassériau 
nos leva a um tipo de sexualidade mais real e próxima.

Tal corpo lembra, em certa medida, as espanholas que Don Mateo encontrava em Sevilha, no romance de Pierre Louÿs;

\footnotetext{
[...] e eu parava mais de uma vez, diante de um admirável corpo feminino, como realmente não existe em outro lugar senão na Espanha, um torso quente, cheio de carne, aveludado como uma fruta e suficientemente vestido pela pele brilhante de uma coloração uniforme e escura, onde se destacam com vigor o astracã crespo sob os braços e as coroas negras dos seios[1]
}

Na descrição de Don Mateo, o corpo feminino é a própria ornamentação, as "coroas negras" ou o "vigor do astracã" são qualidades altamente decorativas e presentes na espanhola. E mais, são qualidades também presentes na Baigneuse, sobretudo a pele brilhante e o torso quente "cheio de carne".

A figura de Chassériau parece compartilhar desse ambiente onde, muito quente, as moças não têm "a menor reserva em aproveitar da tolerância que lhes permite despir-se". Descrição que lembra a crítica de Vaudoyer quando diz que a modelo possui "uma graça quente e como fosforescente [...]"[2].

A erotização nesta figura alongada de Chassériau é marcada de modo forte e sincero, está imersa no onírico e o observador pode contemplá-la sem receios de que ela possa despertar. Neste aspecto, o poema de Amédée Pommier, escrito para L'Artiste, de 1851, parece compreender a obra de Chassériau em diversos aspectos, e insere um elemento que a primeira vista estava escondido, o observador voyeur:

Chut! Avançons sans bruit; gardons de l'éveiller.

Nous pourrons contempler, sous le rideau des branches, L'imprudence dormeuse et ses épaules blanches, Et ses bras arrondis lui servant d'oreiller.

Elle a cru sans péril pouvoir se dépouiller 
De sa longue tunique aux onduleuses manches,

Car nul ne devait voir le satin de ses hanches,

Hornis le flot limpide, heureux de les mouiller.

Mais comment oses-tu, ma baigneuse ingénue,

Sur le gazon des bois t'endormir toute nue,

Dévoilant ton beau corps de la tête aux orteils?

N'est-il plus de sylvain, d'aegipan, de satyre

Qui rôde curieux et lascif, et qu'attire

L'appât d'un sein de neige aux deux boutons vermeils?[3]

O poeta se delicia, avança calmamente, sem barulho, e pode contemplar a banhista. Entretanto, como tamanha beleza pode se descuidar e se exibir dessa maneira, "ingênua", como "dormir inteiramente nua, desvelando seu belo corpo da cabeça aos dedos dos pés"? O poema comporta-se como se o narrador a estivesse observando por trás de uma árvore qualquer, e aos poucos se entrega aos detalhes do corpo que praticamente deita para se mostrar aos olhos dele.

\section{CHASSÉRIAU E OZY}

Há um dado interessante nesta tela e sobre os modos de representação do corpo feminino. Não se trata de um álibi do nu bem estabelecido, aliás, o contrário disto. A imagem traz estampado no rosto a figura de Alice Ozy. Atriz importante naquele cenário, teve curtos relacionamentos com diversas personalidades, entre as quais Théophile Gautier e o próprio Chassériau, com quem manteve uma ligação entre os anos de 1848 e 1850. Este fato curioso teve diversas repercussões, mesmo porque, desejada, Ozy despertava o interesse em inúmeros homens, e consequentemente a inimizade deles com Chassériau. Longe de ser apenas um fait divers, a relação entre Chassériau e Alice Ozy é uma chave importante para compreender a força do quadro.

De fato, a figura alongada na relva parece se mostrar para nós (como indicava Pommier), e sua cabeça direcionada ao espectador, pousada suavemente em seus braços erguidos, atesta a importância e a vontade de exibir a modelo. 
Neste aspecto, os desenhos preparatórios para o quadro podem mostrar certa hesitação do pintor. Especialmente a maneira como iria apresentar a curvatura das nádegas aparentes. Nesses desenhos, o detalhe da dobra que delimita as nádegas das pernas é aparente e apresentado de modo franco e direto. No desenho [Fig 03] este detalhe é retirado. Inclinando a perna direita ainda mais. A própria linha da coxa esquerda aparece mais suavizada.

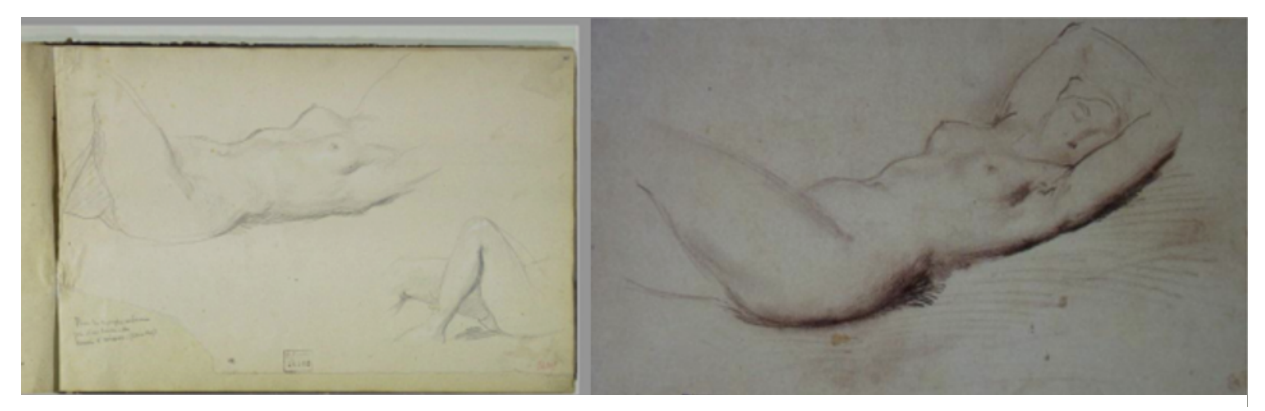

[Fig. 2] Théodore Chassériau. Femme nue étendue, la tête à droite, les mains derrière la tête. 1850. Musée Carnavalet. 22,5 × 41 cm, grafite.

[Fig. 3] Théodore Chassériau. Étude d'un corps de femme allongée vers la droite et études de jambes, Musée du Louvre. Por volta de 1850. 26 × 40,9 cm, grafite.

No óleo sobre tela vemos que, na solução final, o pintor opta por esconder essas partes inserindo a túnica. A presença do tecido entre as pernas da figura pode ser percebida também como um elemento erótico, o contato da pele nua em relaxamento pelo sono no contato e fricção com o panejamento.

É um fato curioso a representação bem demarcada de um rosto muito conhecido naqueles anos. Uma modernidade que antecipa, de certo modo, os nus de 1863 de Manet - sua Olympia e seu Almoço na relva. Um corpo alongado que não quer ter um álibi, mostra francamente a modelo com seus traços distintivos. Portanto, esses corpos nus, sem rostos genéricos ou corpos idealizados, que comumente são atrelados a apenas décadas mais tardes, estão, em partes, presentes desde os anos de 1850, na obra do artista. 


\title{
IDEALIZADA OU CARNAL
}

Podemos, assim como sugere Marc Sandoz[4], comparar a Banhista de Chassériau com os poemas de Théodore de Banville, Les Cariatides, notadamente. Em especial, na descrição da ninfa Clymène:

\author{
Et les arbres touffus, et la brise et les flots \\ Se redisaient au loin d'harmonieux sanglots. \\ Près du fleuve pleurait, parmi les hautes herbes, \\ Une nymphe étendue. A ses regards superbes, \\ A ses bras vigoureux et vers le ciel ouvert, \\ A ses grands cheveux blonds marbrés des reflets verts[5]
}

A comparação de Sandoz parece distante da figura da Banhista. A tristeza e a atmosfera melancólica de Banville são praticamente inexistentes nesta obra de Chassériau. O ponto de encontro, sem dúvida, é a figura feminina que deita na relva: num caso, claramente entregue ao sono pós-banho; no outro, a ninfa e suas lágrimas.

Contudo, uma passagem de Songed'Hiver do mesmo livro talvez seja mais próxima à Banhista:

Et les gens de la fête, émus à son aspect,

Semblaient la regarder avec un grand respect

Par terre, dans un coin, dormait la femme pâle,

Avec une attitude insoucieuse et mâle

Dans ses longs doigts aussi dormait un chapelet

Où l'ivoire à des grains d'ébène se mêlait.

[...]

Ta folle toison hardie

Brille comme l'incendie.

Hôtesse du flot amer,

Ta gorge aiguë étincelle

Dans un rayon qui ruisselle ;

$\mathrm{Tu}$ gardes sous ton aisselle 
Tous les parfums de la mer.[6]

Porém, essa visão muito distanciada em um alhures, que o poeta parece não captar senão imaginativamente, deixa aparentemente a figura da banhista escapar. A imagem realizada por Chassériau coloca-se entre um ser idealizado e carnal[7]. O poema de Banville, neste aspecto, é interessante. Ao mesmo tempo em que sua figura se comporta como uma imagem distanciada, os detalhes da imagem alongada "com uma atitude despreocupada e viril" e "você guarda sob tuas axilas / todos os perfumes do mar" a aproximam de aspectos da Baigneuse.

Se por um lado pode se tratar de uma banhista numa situação distante de nós, em um alhures cujo tratamento dado à composição é etéreo, em contrapartida a mulher se mostra liberta aos seus sonhos, com seu corpo fortemente sexuado, desejado e carnal, concebido quase de modo a criar um embate entre essas características.

\section{O PRAZER ORGÁSTICO DE COURBET E A PUREZA CONTEMPLATIVA DE PUVIS DE CHAVANNES}

Entretanto, pode-se questionar, por exemplo, como esta obra, profundamente de espírito moderno, pode se relacionar com Courbet ou Manet. Para Pomarède, pintado em 1850:

\footnotetext{
[...] entretanto, apenas dois anos antes das Baigneuses de Gustave Courbet (Musée Fabre) e, sobretudo, apenas treze anos antes de Le Dejeunersurl'herbe de Édouard Manet (musée d'Orsay), a Baigneuse endormie propunha uma atitude quase idêntica .[8]
}

Consideração também remarcada por Vaudoyer:

Esta figura incarna o idealismo sensual, pode-se opor a ela os nus deitados de Goya, de Courbet e de Manet, os quais restam submetidos e de alguma forma condenados aos prestígios da única realidade[9]

Tanto Courbet como Manet são considerados verdadeiros pilares da arte moderna e guardam importantes elementos que vão ao encontro da Banhista de Chassériau. No caso de Courbet, em específico, mais do que 
se relacionar com as Banhistas do Musée Fabre de Montpellier, em que percebemos a presença de elementos similares (a vegetação que se fecha sobre os personagens ou a banhista quase nua), a obra de Chassériau mantém-se mais próxima a imagens como Les demoiselles des bords de la Seine (Été), de 1857 [Fig. 4]. Em primeiro lugar a figura feminina está alongada, seus estados de dormência e torpor e a presença das águas, neste caso, o rio Sena, são próximos à ideia da Baigneuse.

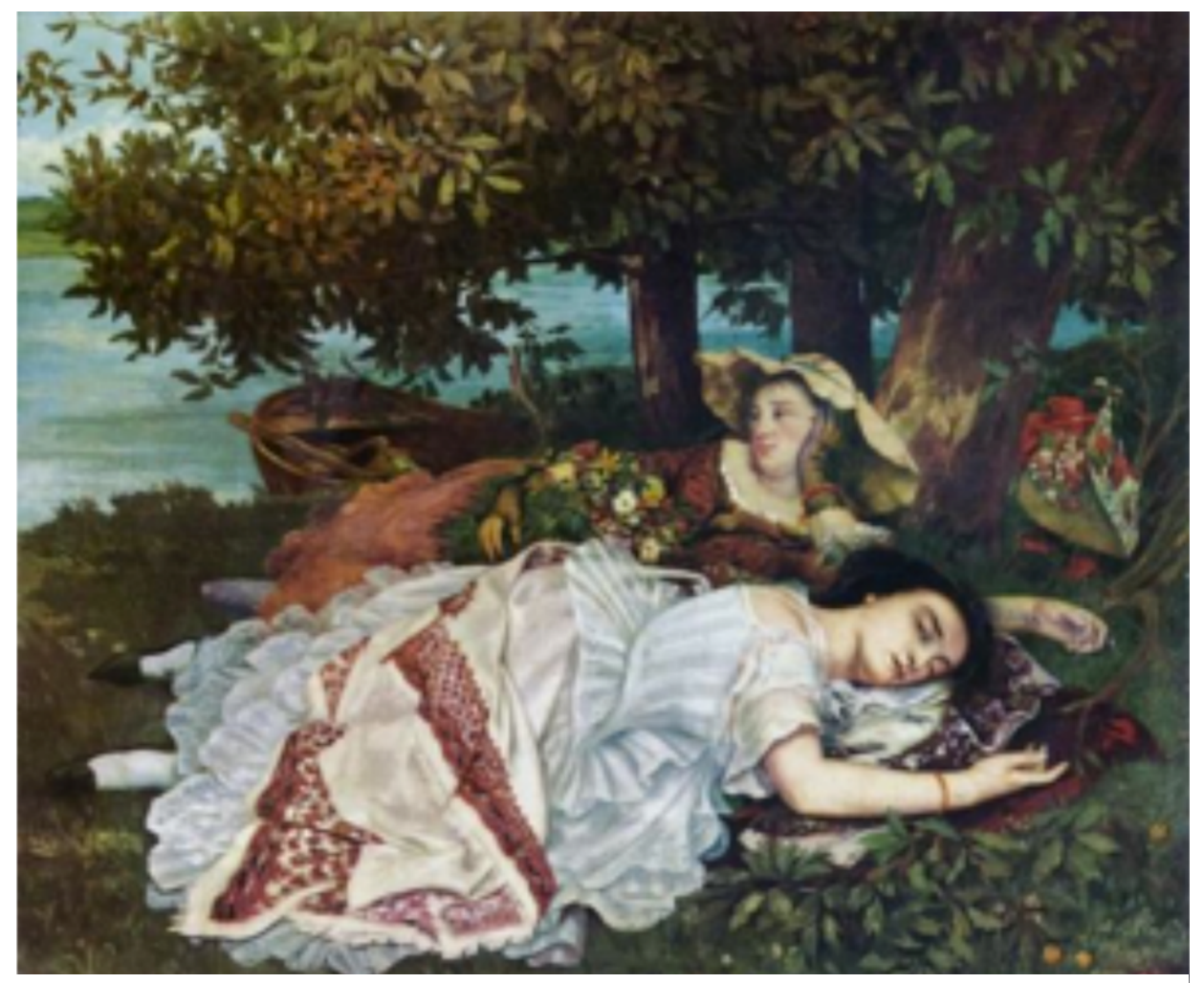

[Fig. 4] Gustave Courbet, Les demoiselles des bords de la Seine (Été), 1857. Le Petit Palais. 174 x 206 cm, óleo sobre tela.

A imagem de Courbet neste aspecto, mesmo se tratando de duas mulheres semivestidas, possui uma atmosfera compatível com a imagem da Baigneuse. As figuras femininas entregues ao torpor do verão estão próximas às águas e abaixo das árvores. A mulher em primeiro plano não está totalmente vestida, uma parte de sua roupa lhe serve de lençol e deixa à mostra suas vestes íntimas. 
Jorge Coli salienta algumas características das figuras femininas em Courbet:

\author{
Estupidez e inação correspondem bem às características de boa parte \\ das mulheres pintadas por Courbet. Les demoiselles du bord de la Seine, \\ por exemplo. Seus corpos aderem ao solo em uma gravidade inerte. \\ Elas se mostram incapazes de toda atividade e, sobretudo, elas não \\ pensam, digerem cansadas.[10]
}

Verdade que também pode ser atribuída ao quadro de Chassériau. Evidente que na tela de Courbet esses elementos estão mais intensos, contudo, são como características potencializadas dos elementos que estão presentes na figura da Banhista.

Diferente de Tamaris, 1886-1887, de Puvis de Chavannes, que não faz parte daquelas figuras que "sobretudo não pensam". Ao contrário, a imagem etérea e profundamente introspectiva, para além do descanso, medita. Porém, a imagem, como podemos ver em relação [Fig. 5], é extremamente próxima à de Chassériau. A figura está imersa em um ambiente cujo céu está quase inteiramente tomado por nuvens carregadas. A mulher estendida segura delicadamente um galho. Seus fartos seios são desprovidos de mamilos e sua pele de pelos. Sua sexualidade dá lugar a um ideal de pureza contemplativa. 


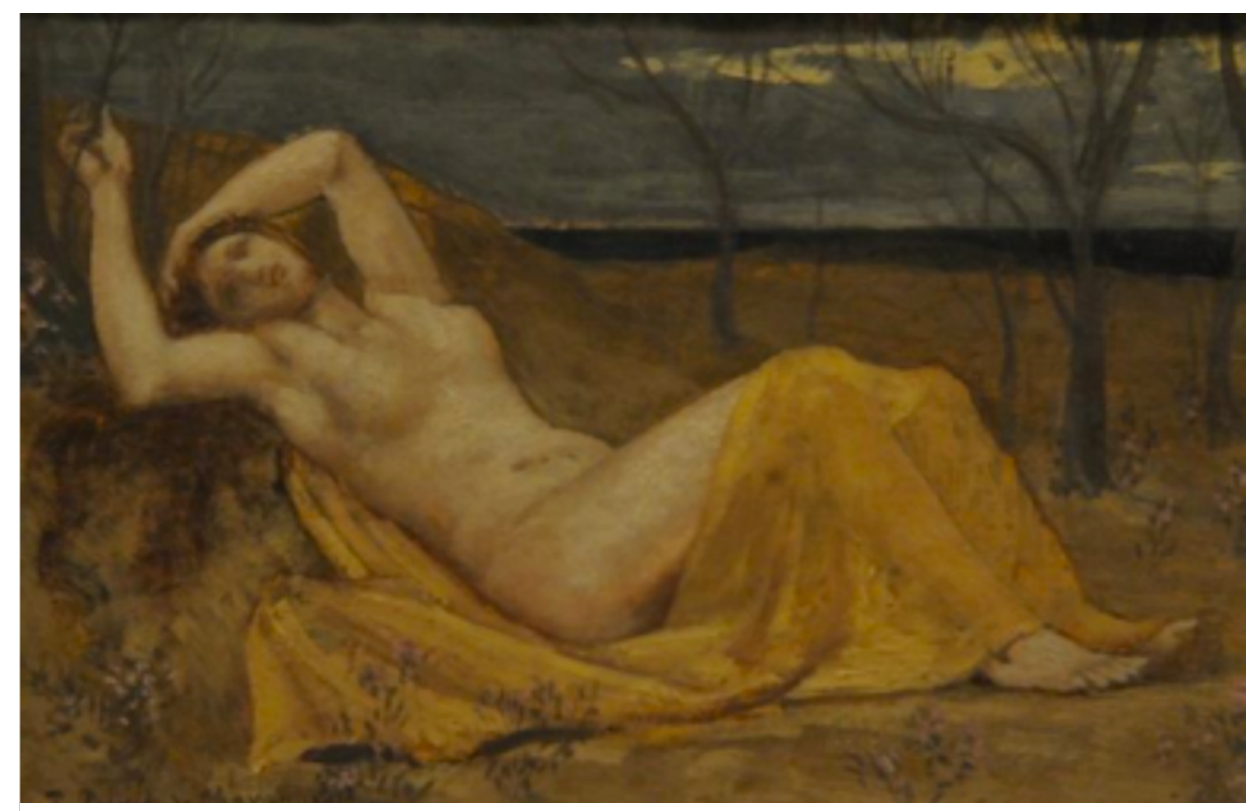

[Fig . 5] Pierre Puvis de Chavannes, Tamaris, 1886-1887. The Metropolitan Museum of Art. 25,4 × 39,4 cm, óleo sobre tela.

\section{VOYEURISMO E O PRAZER DO CORPO NA RELVA}

Estas características, em parte, voltam com a ideia do voyeur, explorado primeiramente sob o viés do poema de Pommier. Contudo, podemos avançar um pouco apontando para outras direções.

Os sentimentos indicados também são partilhados em algumas cenas do filme The Immoral Mr. Teas, primeiro longa metragem de Russ Meyer, de 1959. As mulheres, quase o inverso de Tamaris de Puvis de Chavannes, são desinibidas e provocadoras. O filme se concentra em uma espécie de delírio do protagonista, no qual ele insiste em ver as mulheres que o circundam nuas ou seminuas e, mais do que isto, provocadoras. $\mathrm{Na}$ trama ele é sempre um voyeur, e a cena em que mulheres de corpos abundantes se deitam no trigal é particularmente interessante.

Elas estão se refrescando em um dia quente à beira de um rio. A natureza é um lugar de prazer: do sono, da brincadeira ou dos gozos. A passagem acrescenta um elemento invisível, mas presente de algum modo nas imagens de Chassériau e Courbet: o observador. Mr. Teas, atrás das árvores, quase como Acteão, se depara com a beleza do corpo feminino. 
Ele espreita, se esforça e com bastante eficácia consegue admirá-las por algum tempo [Fig. 6].

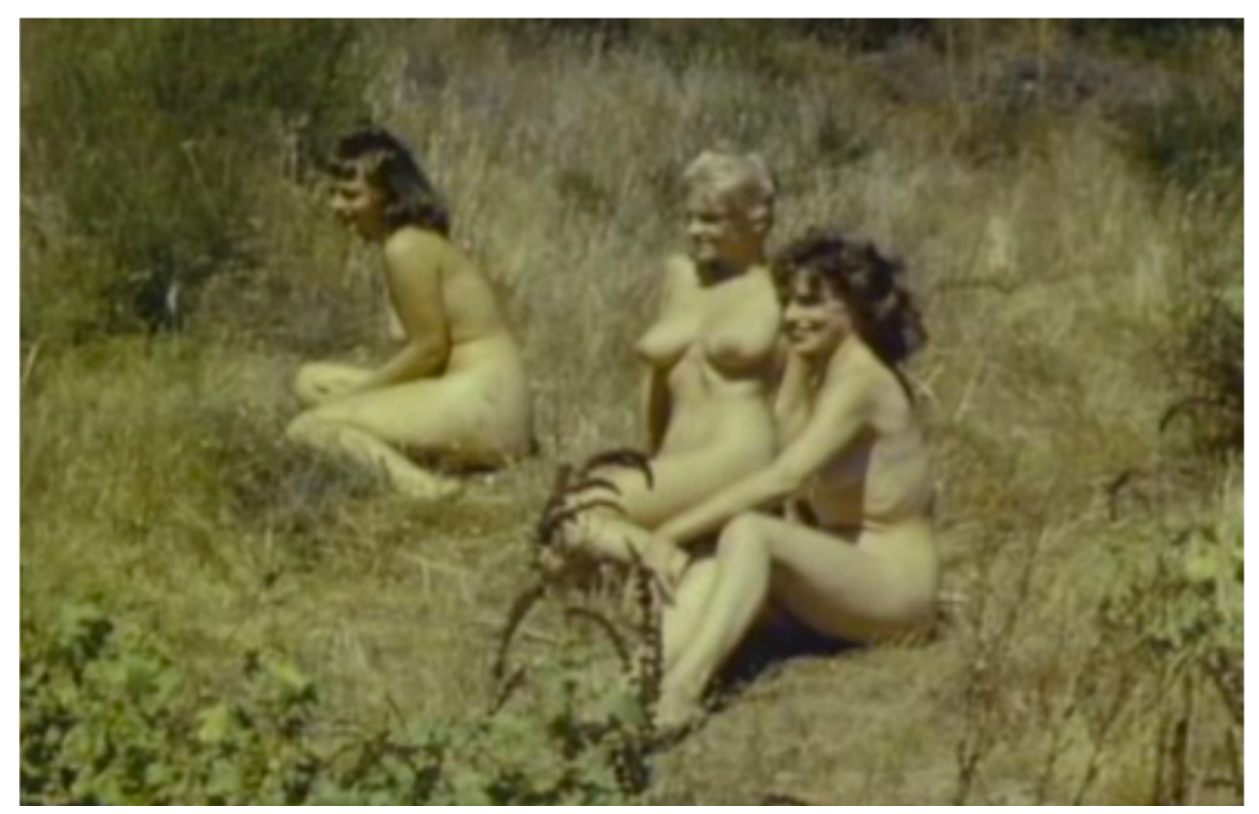

[Fig . 6] Russ Meyer, The immoral Mr. Teas, 1959.

O observador nas obras de Courbet e Chassériau está pressuposto, embora invisível. No caso de Courbet, uma cartola é aparente e está virada no barco, nos sugerindo a presença masculina naquele ambiente. $\mathrm{Na}$ Banhista de Chassériau, por sua vez, não há elementos indicativos da presença de homens. Contudo, como discutido a partir do poema de Pommier, um voyeur também pode ser considerado.

Estas obras possuem uma força erótica evidente, que ganha um caráter franco e direto nas imagens realizadas supostamente por voyeurs e disponíveis aos montes pelos sites na internet[11]. Em um deles, vemos a imagem de uma mulher nua [Fig. 7], aparentemente dormindo na relva. A legenda não deixa dúvidas de que se trata de um sono pós-gozo, realizado após a masturbação: "Masturbação no campo de uma moça".

Não vemos o rosto da figura. Todavia, seu corpo está disponível ao observador, cujo olhar entrecortado por algumas folhas, esconde-se em um prazer calado e imaginativo como o da mulher deitada. O corpo 
branco da figura alongada é dourado pelos raios do sol. Ao seu lado, um conjunto de roupas sugere que se despiu há pouco tempo, para aproveitar o calor e os prazeres do sol e da relva.

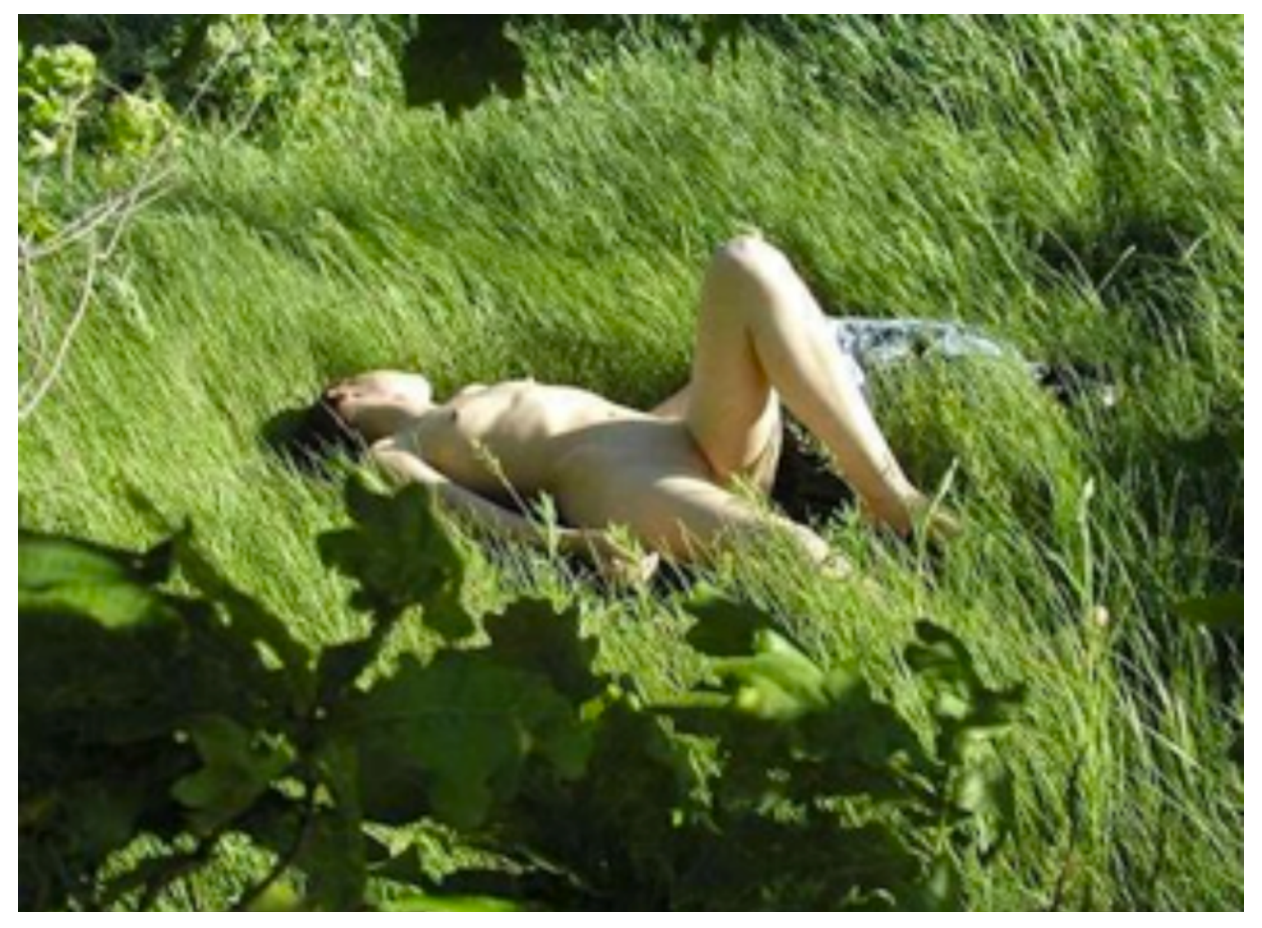

[Fig . 7] Anônimo, s/n, 2009.

A frase que acompanha a imagem é interessante:

Uma mulher alongada nua na natureza, aproveitando da doce carícia dos raios de sol sobre sua pele branca. Uma ninfa que se seca ao sol, levada pelos sonhos dos barulhos das ondas...[12]

A frase também pressupõe as águas, que no caso da Banhista de Chassériau são aparentes. A incrível descrição poderia ipsis litteris acompanhar a imagem da Banhista adormecida.

A poética que se desvela em uma imagem como esta, e que está presente também na tela de Chassériau e mais evidentemente no trecho do filme de Russ Meyer, é aquela do erótico, do contato do corpo nu com os lugares dominados pela natureza. Livre de aspectos rigorosos ou 
estruturados da arquitetura. A imagem sugere uma carícia não apenas do roçar na grama, mas do vento sobre o corpo.

\section{O VOYEUR ATROZ NO CINEMA}

Este tipo de representação ganha força e de certo modo é levado às últimas consequências em algumas imagens cinematográficas. É importante notar como as questões tratadas a partir da Baigneuse endormie estão incrustradas em certa produção do cinema. Sob este viés, as imagens escolhidas aqui são relevantes para que se entenda uma interpretação dada a um tema caro à História da Arte.

A presença constante de um observador perverso, que espreita a mulher como uma vítima, está presente em diversos filmes, particularmente no final da década de 1970 e começo de 80 [13].

No filme de Meir Zarchi, I spit on your grave[14], de 1978, por exemplo, uma mulher que se retira em uma cabana distante para escrever, acaba sendo alvo de um grupo de amigos sádicos que a agridem e a estupram diversas vezes. Em algumas cenas, mesmo quando a presença masculina ainda não é concreta, vemos o observador pressuposto pela astúcia da filmagem.

Contudo, os desenvolvimentos destes filmes não se esgotam no prazer da visão, do flagra ou mesmo da masturbação, como no caso da fotografia da internet. Antes, se apresentam como um limite terrível no conjunto destas representações. O mesmo acontece com o filme de Danny Steinmann, Friday the 13th: A New Beginning, de 1985. A imagem nos mostra uma moça alongada na relva [Fig. 8], em uma posição extremamente semelhante à pose da figura feminina no quadro da Banhista de Chassériau. Ela não está se secando ou apenas aproveitando os prazeres de sua pele próxima à natureza. Está esperando que seu companheiro, com o qual fazia sexo, retorne aos seus braços. O que era um voyeur calado no quadro de Chassériau se metamorfoseia em um filme como este. 


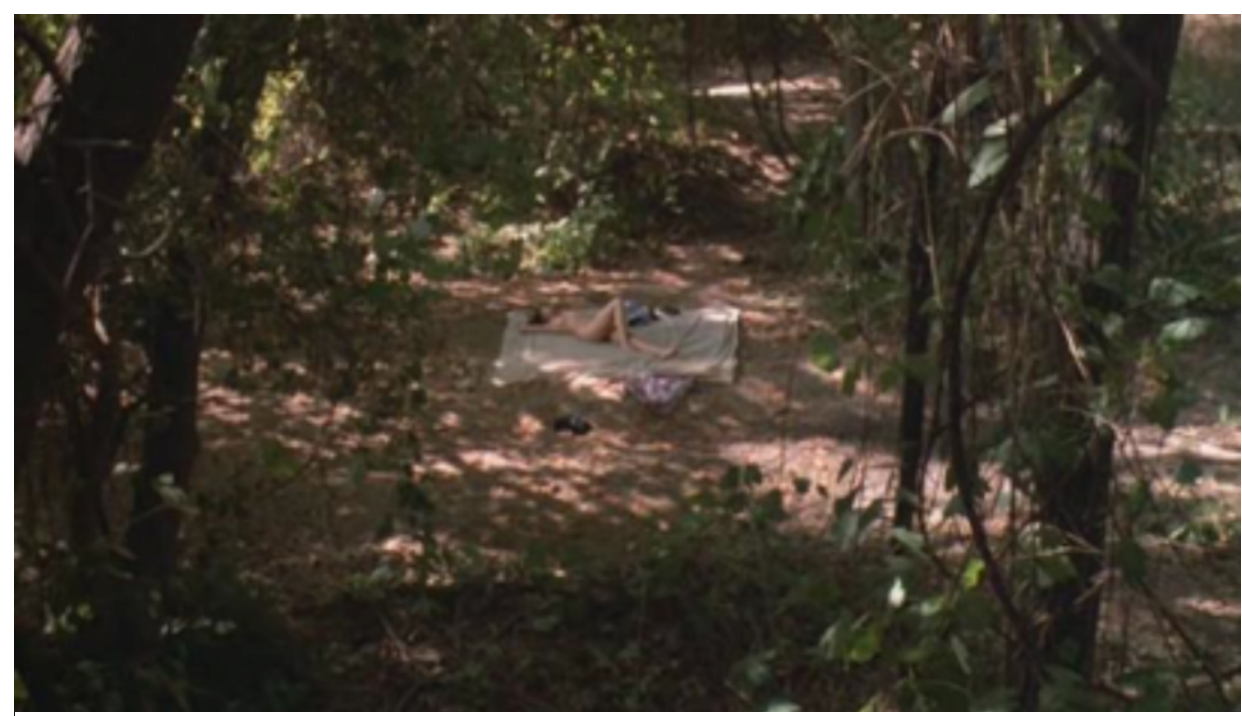

[Fig .8] Danny Steinmann, Friday the 13th: A New Beginning, 1985

O observador não precisa mais se espreitar para admirar a mulher, posto que é partícipe da cena. Contudo, sabemos que ainda há um voyeur, Jason[15], cujos olhares camuflam-se na paisagem. Aqui, o desejo sexual é transmutado na gana assassina e vingativa de um psicopata.

\section{DO ÁLIBI E DA IRONIA}

Diverso da maneira pela qual Feuerbach concebe sua ninfa [Fig. 9]. Ela está inserida na relva e mesmo assim dorme protegida, pois seu corpo repousa em uma cama. A composição, como na banhista de 1850, é realizada de maneira a apresentar as belas formas de um corpo feminino. Desta vez, porém, o álibi da ninfa está perfeitamente presente. O rosto inclinado libera a cabeleira que se mistura com a pele do animal que lhe serve de lençol. Mais do que isto, a figura de Feuerbach, com a forte presença da pele de pantera, o rosto mesmo no sono forte e duro flerta com o tema da Femme Fatale. 


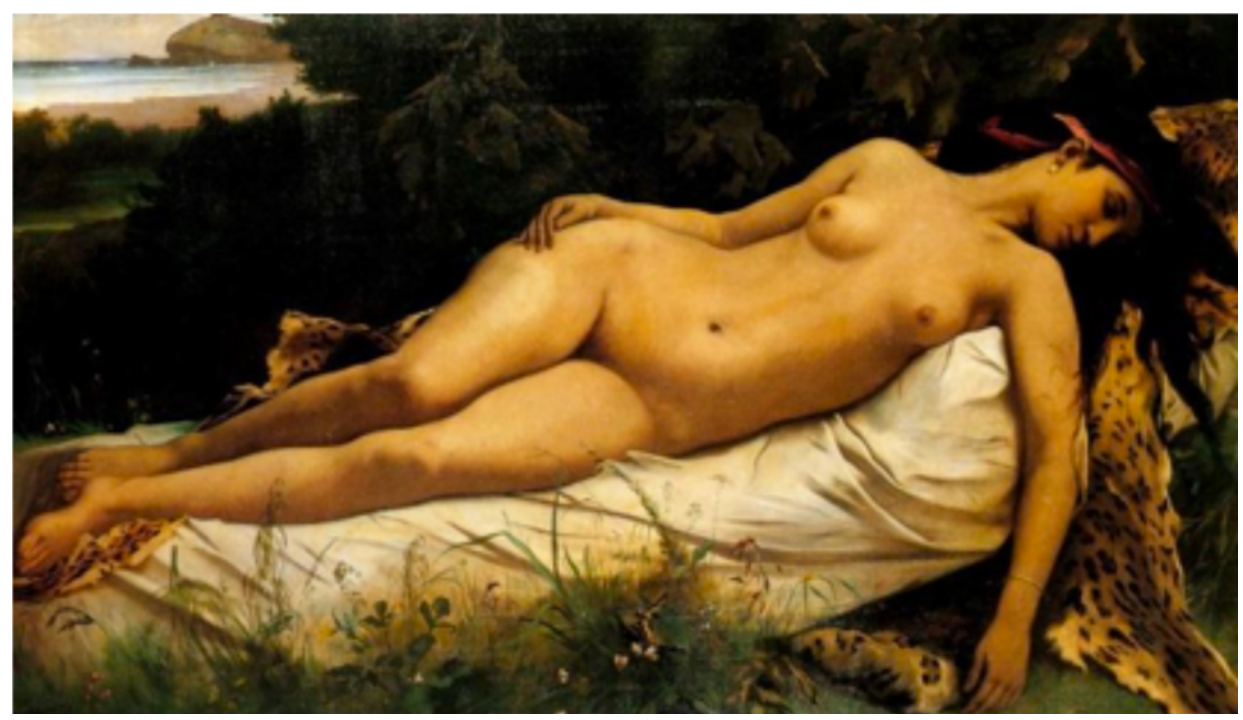

[Fig . 9] Anselme-von Feuerbach, Ninfa adormecida, 1870. Germanisches Nationalmuseum. 112 × 190 cm, óleo sobre tela.

Ela se apresenta frontalmente ao espectador em um espaço no qual notamos, no horizonte, as águas e a areia de uma praia. Entregue ao sono, tal qual a figura de Chassériau, a ninfa de Feuerbach parece não sentir os prazeres orgásticos que a imagem da banhista de 1850 sugere.

Um tipo de composição que desagradaria Huysmans, como escreve em seu Le Salon de 1879, em que reconhece como dignas as figuras na relva, em "plein air". Contudo irreais, uma vez que poucos artistas realmente pintaram suas modelos diretamente na natureza:

Os pintores sempre me espantam. A maneira pela qual eles entendem o nu, en plein air, me deixa estupefato. Eles elaboram ou deitam uma mulher sob as árvores, ao sol, e eles tingem a pele como se ela estivesse estendida em um quarto com calefação, sobre uma toalha branca, ou em pé contra uma tapeçaria ou sobre um papel de parede [...] Eu bem sei que se podem ver pouquíssimas mulheres nuas sob as árvores. É um espetáculo instrutivo que as regras policiais proíbem; mas, enfim, isso pode existir.[16]

Neste momento, Huysmans que não negava a arte do passado, estava 
certamente interessado na arte moderna. Achava tal processo das mulheres na relva tão "monstruoso quanto um pintor que não coloca seus pés para fora e compõe, mesmo assim, ao acaso, uma paisagem em seu ateliê"[17]. Contudo podemos reafirmar nessas próprias obras encaradas por Huysmans com certa dose de falsidade, não natural, uma propensão realista.

Como no caso da figura apresentada por Vallotton [Fig. 10], que se insere no entremeio da banhista de Chassériau e a deusa de Giorgione. A figura feminina em primeiro plano lembra a Banhista adormecida por sua posição, pelo braço erguido e, sobretudo, pela axila revestida de pelos e as manchas mais claras no corpo da figura alongada. Todavia a mão que protege o sexo faz referência a Giorgione e, certamente, a Manet. A obra intitulada Roger délivrant Angélique é também uma espécie de homenagem irônica ao quadro homônimo de Ingres de 1819.

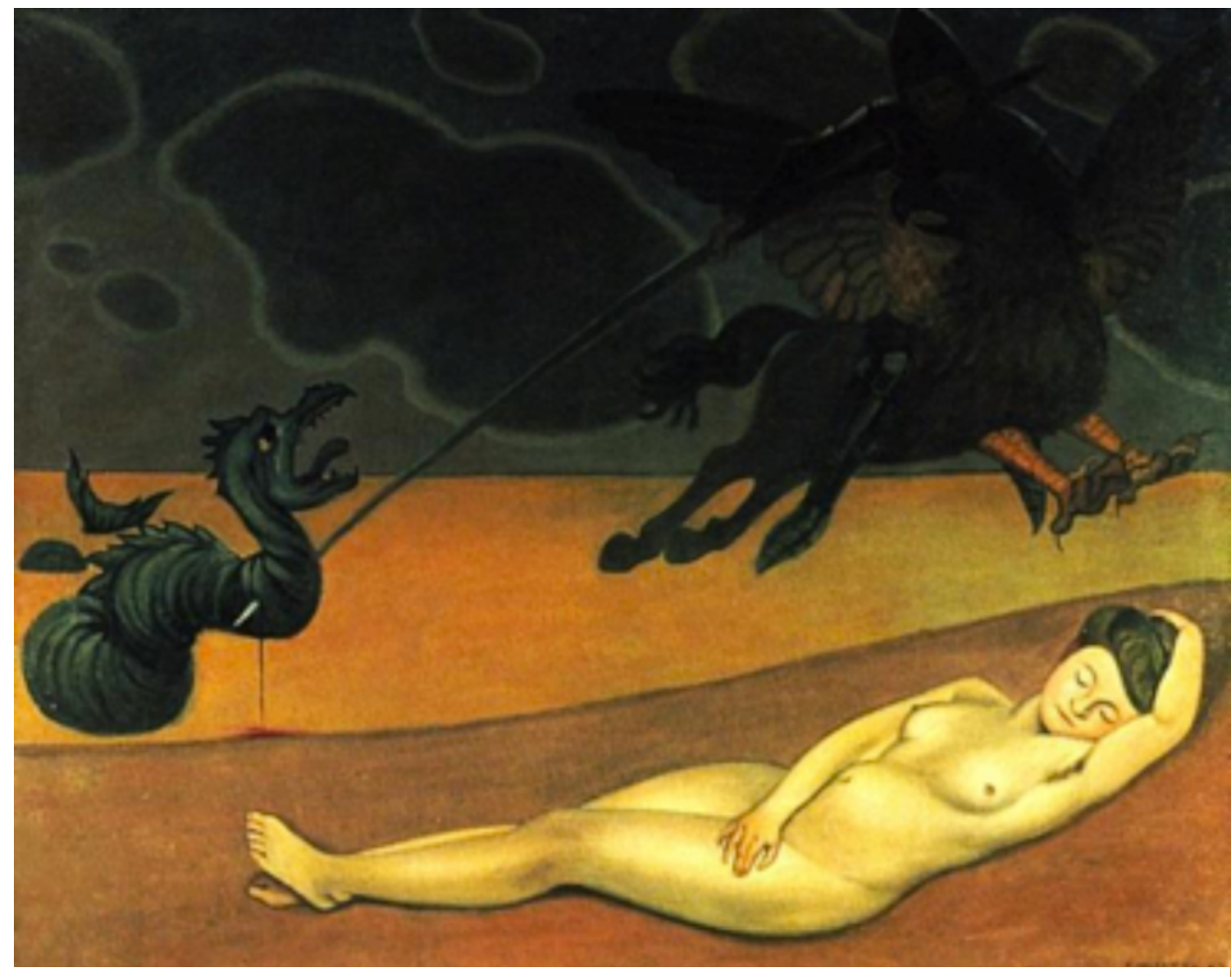

[Fig . 10] Félix Vallotton, Roger délivrant Angélique, Kunsthaus. 1907. 80 x $100 \mathrm{~cm}$, óleo sobre tela. 
Ao invés de mostrar Angélica sofrendo, quase atacada pelo monstro marinho, a princesa em Vallotton está evidentemente mais para uma banhista que descansa, cochila, enquanto Rogério derrota o monstro.

\author{
Podemos indicar o que afirmava Baudelaire no salão de 1846. Não há \\ dúvida na afirmação do escritor de que o nu "é tão frequente e necessário \\ na vida antiga", mas o elemento novo que surge "é a beleza moderna" [18] \\ . Da imagem assegurada pelo álibi da ninfa de Feuerbach à figura nua na \\ relva da Baigneuse, Chassériau está no centro dessa discussão. A \\ presença da mulher nua deitada na relva, como vemos, é um forte tema \\ que se estende claramente até os dias atuais. A ligação da imagem do \\ artista com aquelas do cinema ou da fotografia em relação à literatura é \\ imprescindível na análise da imagem.
}

[1] Louÿs, Pierre. La Femme et le Pantin. Paris : Gallimard/Folio, pag. 68.

[2] Op. Cit.

[3] POMMIER, Amédée. «Sonnets sur le salon de 1851 : Baigneuse endormie près d'une source ». In L'artiste. Revue de Paris. 5 série - Tome VI. Paris : Aux Bureaux de L'Artiste, 1851. Tradução livre, objetivando simplesmente a compreensão do conteúdo, sem as preocupações rítmicas e harmonizadas de Pommier :

Silêncio! Avancemos sem barulho: não a acordemos.

Podemos contemplar sob a cortina os ramos,

A imprudente adormecida e seus ombros brancos,

E seus braços roliços servindo-lhe de travesseiro.

Ela pensou não ter perigo em poder se despir

De sua longa túnica com manchas ondulosas,

Pois nada deveria ver o cetim de seu quadril,

Exceto a límpida inundação, que a molha feliz

Mas como ousa minha banhista ingênua,

Sobre o relvado adormecer totalmente nua,

Desvelando teu belo corpo, da cabeça aos pés?

Não é mais Silvano, Aegipan ou Sátiro

Que à espreita, curioso e lascivo, atrai

A isca de um seio de neve com dois botões vermelhos?

[4] Sandoz, Marc. Théodore Chassériau: 1819-1856. Catalogue raisonné des peintures et estampes. 1ed. Paris: Arts et Métiers Graphiques, 1974. Pag. 298.

[5] Banville, Théodore de. CEuvres de Théodore de Banville. Paris: Alphonse

Lemèrre, 1889, pag. 143.

$\mathrm{E}$ as árvores espessas, a brisa e as ondas

Diziam de novo, longe de soluços harmoniosos.

Perto de um rio chorava, entre a grama alta,

Uma ninfa estendida. Com a sua bela aparência,

Com seus braços vigorosos e em direção ao céu aberto, 
Com seus grandes cabelos loiros marmorizados de reflexos verdes

[6] Op . Cit. pag. 135-137.

$\mathrm{E}$ as pessoas da festa, atraídas pela sua aparência,

Pareciam olhá-la com um grande respeito

No chão, em um canto, dormia a mulher pálida,

Com uma atitude despreocupada e viril

Em seus longos dedos também dormia um rosário

Em que o marfim e grãos de ébano se misturavam.

[...]

Seus loucos e fortes pelos abundantes

Brilham como o incêndio.

Anfitriã da inundação amarga,

Tua garganta aguda fagulha

Em um raio que corre ;

Você guarda sob tuas axilas

Todos os perfumes do mar

[7] "O nu a duras penas desce de seu pedestal e se incarna. Apesar dos pelos

indiscretos que remarcamos sobre a Banhista adormecida de Chassériau, apesar do desejo visível do pintor humanizar sua figura e de individualizá-la, ela permanecerá, como sua modelo giorgionesca, velada de ideal". Haddad, Michèle. La divine et l'impure: Le nu au XIXe. Paris : Éditions du Jaguar, 1990, p. 66.

[8] Pomarède, Vincent. «Baigneuse endormie près d'une source » in Prat, LouisAntoine et. Al. Chassériau. Un autre romantisme. 1ed. Paris: RMN, 2002. p. 295.

[9] Vaudoyer, J-L. «Les portraits de Chassériau ». inFeuillets d'Art. No 3, Paris : Lucien Vogel, 1921. pp. 37-42.

[10] COLI, Jorge. L'atelier de Courbet. Paris: Hazan, 2007, pag, 72.

[11] Jorge Coli, em seu artigo "Exposição, ocultação, contemplação: o olhar e o sexo feminino", explora em um caminho análogo a imagem da vulva aparente. Para o autor, "No mundo interminável dos desejos intensos que é a internet, as imagens licenciosas são infinitas. Trata-se de desejos inefáveis, intangíveis, "virtuais" (bela etimologia, do latim virtus, que também dá origem, numa gênese paradoxal, à palavra virtude), ou seja, existindo apenas em potência e não em ato, como sonho e irrealidade, são imagens que alimentam, e se alimentam, dos desejos humanos, exatamente como as obras de arte". In Revista de História da Arte e Arqueologia. Campinas: IFCH, n. 16, jul-dez. 2011, p. 139.

[12] "Femme nue dans la nature" (acesso em julho de 2012 ).

[13] Sobretudo uma produção que começa a ganhar força com filmes como I spit on your grave, de 1978, de Meir Zarchi; Friday, the 13th, de 1980, de Sean S.

Cunningham; e The Last House on the Left, 1972, de Wes Craven. Este último, uma espécie de atualização forte e por vezes irônica do filme $A$ fonte da donzela, 1960, de Ingmar Bergman. A mulher na relva e os olhares indiscretos são ligados quase naturalmente às atrocidades que se desenvolvem nestas tramas.

[14] O diretor Steven R. Monroe, em 2010, faz o remake do filme com o mesmo nome. Entretanto, o longa de Monroe é mais monocromático e pretensiosamente mais escatológico, embora funcione com menos potência que a filmagem de 1978 . [15] Famoso personagem criado a partir do episódio I da série Friday the 13th, de 1980, e dirigido por Sean S. Cunningham. Neste primeiro filme, o principal assassino ainda não é Jason e sim sua mãe, a Sra. Pamela Voorhees. O desenvolvimento de Jason como assassino se esboça no fim do primeiro filme e se consolida a partir do episódio II, de 1981, dirigido por Steve Miner.

[16] HUYSMANS, Joris-Karl. « Le Salon de 1879 ». In Écrits sur l'art: 1867-1905. Édition établie par Patrice Locmant. Paris : Bartillat, 2006, p. 123.

[17] Op. cit.

[18] Baudelaire, Charles. «Salon de 1846 ». in Critique d'art suivi de Critique musicale. Paris : Gallimard, 1992, p. 156. 


\begin{tabular}{|c|c|}
\hline celeuma & número 3 | dezembro 2013 \\
\hline & $\begin{array}{l}\text { MARTINHO ALVES DA COSTA JUNIOR é doutor em História da Arte pelo } \\
\text { IFCH/Unicamp e pesquisador do Centro de História da Arte e } \\
\text { Arqueologia (CHAA). }\end{array}$ \\
\hline
\end{tabular}

